\title{
Reference rover: The hesitant patron's best friend
}

\author{
By Jennii L. Ramirez
}

\section{Roving gives interns great experience}

ike an untrained pup, eager yet lacking in practical experience, I present myself at Diablo Valley College (DVC) Library to begin an internship in the Reference Department.

Betty Bortz, head of reference at the community college, proposes that I initially circulate in the area of the library's OPAC terminals and CD-ROM periodical stations, assisting patrons with the library's electronic databases. She had recently read an article by Adeane Bregman and Barbara Mento in CERL News ("Reference roving at Boston College," November 1992) promoting "reference roving" and feels that this approach may provide a good introduction to assisting patrons. The authors of the article suggest that the proliferation of electronic databases contributes to a growing need to provide assistance at the point of use.

It is Brotz's opinion that many patrons at the DVC Library need instruction in the function and usefulness of OPACs and CD-ROM database resources. While those library resources are becoming more varied and complex, students are matriculating to the college ill-prepared in their use. Bibliographic instruction in California high schools is becoming more scarce due to budget cutbacks necessitated by the state's money woes. Regardless of their lack of preparedness, many patrons seem reluctant to approach a reference librarian for assistance with the equipment. The librarians suspect that this hesitancy may be in part due to the distance between the reference desk and the vari- ous electronic workstations, a range from 10 to 30 feet.

\section{Evaluating roving}

I am supposed to test whether the rover approach will be accepted by the patrons, will prove to be worthwhile to users of the library's electronic resources, and should be considered for implementation by regular staff. The proposed duties sound to me like a good way to ease into reference work. After all, Infotrac and other CD-ROM periodical databases-ALICE (the library's OPAC), Melvyl, and a few other local public library online and CD-ROM catalogs-are a much smaller universe to deal with than the library's entire reference collection. My confrontation with "Reference Desk Phobia" and exposure of my lack of reference savvy are postponed, or so I think.

Wearing a nametag proclaiming my status as a librarian assistant, I venture forth to assist electronic database users. No one approaches me. After several minutes of circulating among the patrons at the database workstations, I conclude that proactive measures are called for or I may wander about aimlessly for the rest of the day. Wearing a smile and with an upbeat tone, I ask users, "Excuse me, are you finding what you need?" and I have numerous takers in my first few hours of roving.

When patrons accept my offer, I find traditional reference work is often called for after all. The students don't just need to know how to locate a citation on a specific topic or the record for a particular library title. Instead, their inquiries indicate that they require direction on how to approach a question (e.g., "Where can I find information on the Alliance for Progress?" 
Struggling to survive in the face of severe federal funding cutbacks, more and more Native American tribes have turned to gambling to keep their reservations going, With some reservation casinos grossing millions of dollars a year, the plan has seemed successful. But some state legislators

\section{IN their Latest fight With the government, Native Americans HAVE RESORTED TO SOME POWERFUL NEW WEAPONS.}

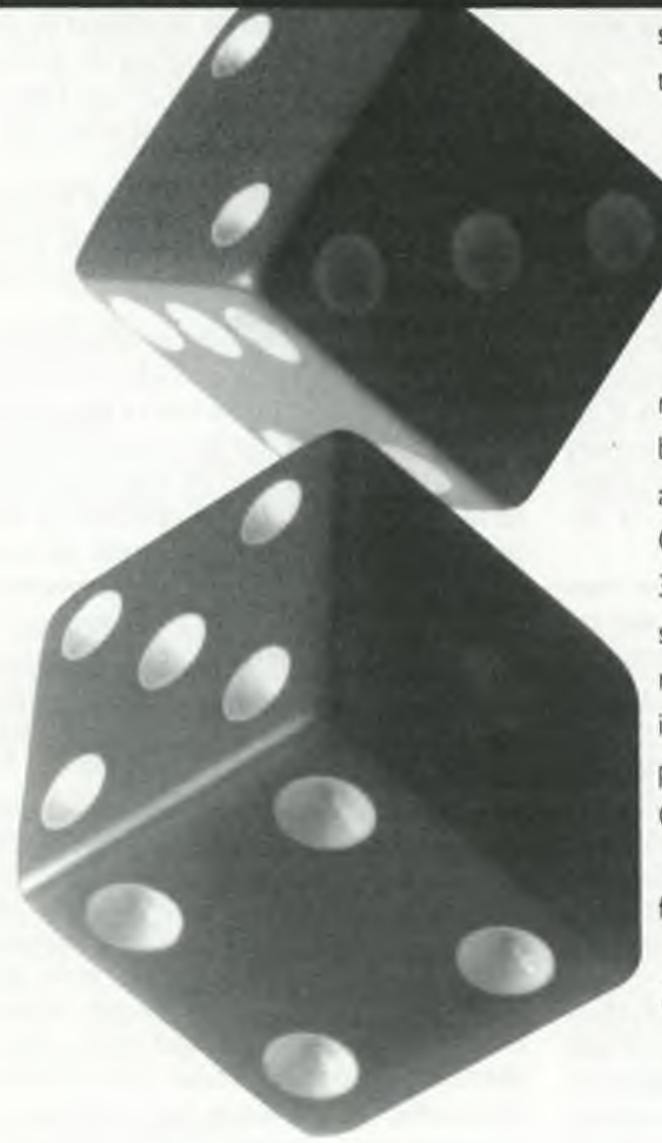

say it's bad medicine. And so the conflict between the cowboys and the Indians continues...

Legislation on Native American casinos is an issue that packs significant national import. Which is why it's one of the thousands of subjects covered by PAIS International.

Coverage that crosses all borders From Congressional legislation to banking regulations, PAIS International provides a unique breadth of coverage on state, interstate, national and international levels, In all, PAIS online and $C D \cdot R O M$ indexes give you access to over 350,000 journal articles, government documents, statistical directories, monographs, conference reports and more. And to provide an unrivaled international outlook, PAIS references literature published around the world in English, French, German, Italian, Spanish and Portuguese.

So the next time you're shooting for hard-tofind data, don't gamble. Use PAIS.

Public Affairs Information Service, Inc.

521 West 43rd Street, New York, NY 10036-4396 800-288-PAIS, 212-736-6629 (in NYC) Fox: 212-643-2848

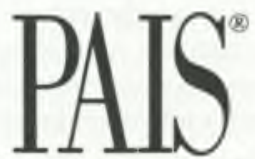

No one looks at the world like PAIS

In Print: PAIS INTERNATIONAL IN PRINT ${ }^{\circ}$ - PAIS SUBIECT HEADINGS Online Through: DATA.STAR + DIALOG + OCLC • RLG On CD.ROM: PAIS ON CD-ROM. PAIS INTERNATIONAL ON SILVERPLATTER On Magnetic Tape: CONTACT PAIS FOR INFORMATION 
or "I need to do a speech on one side of a controversial topic. Where can I find topic ideas?"). I am on my feet rather than sitting behind the reference desk, but I am conducting reference interviews and answering reference questions nonetheless.

\section{Advantages for the intern}

Many of these academic library neophytes and I have something in common: we are facing the fear of being discovered as lacking in library expertise. Together we overcome some of our shortcomings. As I help a patron locate the information he or she lacks, using electronic or print resources, we both become more adept in the use of library materials. Although there are many times when I must refer the user to a veteran librarian, my confidence grows as my experience and the number of successful interactions increase.

The advantages of roving for the library school student are the same as those of a traditional reference internship. The experience affords an opportunity to become acquainted with library resources, to gain experience assisting users, and to overcome the anxiety present when first attempting to integrate classroom-acquired knowledge and library resources with a user's information need.

Reference roving, in fact, is better than working from a reference desk in some respects. The amount of contact with patrons is greater when roving. Not only does the rover's offer of assistance in itself provide an opportunity to become more comfortable in interpersonal communication with patrons, but the offer is often appreciated and accepted. It is my experience that I get more practice at reference interviewing and assisting patrons with inquires when I rove than when I wait for them to approach me at the desk.

Although many of the questions I elicit prove to be merely directional (e.g., "Which computer has journal articles on health topics?"), often these interactions provide an opportunity to instruct the patron in the use of an electronic database. And, with rapport growing, the patron frequently reveals the information need, and a reference interview is underway after all.

While roving, I feel no pressure to rush when assisting a patron. Because there is no designated place for them to line up to await my help and there is no telephone to beckon me, I remain unaware of any need other than that of the patron at hand. I feel that I can take as much time as required to assist each patron fully. But the rover is not alone in reaping benefits from this arrangement. The pluses to the patron are manifold.

\section{Patron benefits}

1) Since the intern's only reason for circulating is to offer assistance, this indicates to patrons that they are not expected to know how to use the resources. That signal-that it is okay not to know and therefore it is okay to get helpis reassuring to patrons.

2) Because assistance is offered to the patron at the point of use, patrons do not have to abandon their workstations to get help. They need not risk losing their turn when that area is busy.

3) There is no desk separating the patrons from the rover. This close physical proximity helps break down the barrier to open communication.

4) The patron has the opportunity to learn through a hands-on approach. The rover can instruct the patron in the use of the equipment with the patron doing the actual keying-in of data. This combination of visual, verbal, and tactile instruction can be effective in training users in the function of electronic resources.

5) A one-on-one approach provides more individualized attention than group bibliographic training. Feedback from the patron can direct the instruction, focusing it on the areas in which skills are weak. And, examples used in that instruction can be selected to be relevant to the particular patron's need.

6) Although reference roving interactions are of a more public nature than those at the reference desk, I believe this, too, is an advantage more often than not. Even those patrons who never ask for help can benefit from this approach. While helping one patron, others may overhear the discussion and learn along with the "official" trainee. Those who initially turn down offers of assistance, but are in close proximity to rover interactions with other users, frequently request help after all. Observing that the rover provides nonjudgmental, friendly assistance may embolden them to ask for help.

\section{Points to ponder}

I see reference roving in a positive light overall, but I do have a few concerns about it. Some electronic resource users may feel intimidated by the presence of the rover. I find that I am 
"barking up the wrong tree" at times, interrupting the research of patrons who are doing well on their own. Some patrons may feel that their privacy is being invaded by an offer of assistance or just by the rover's presence. Or they may feel self-conscious about their lack of retrieval expertise and would prefer not to be observed while they work. Perhaps, over time, an experienced rover can learn to detect indications that the patron does not welcome help.

Another concern is the possibility that offering assistance may rush the patron toward an answer when he or she is still probing a topic and developing a question. The rover should try to discern which stage of research patrons are in, allowing them time to browse and sample databases. Rovers might benefit from training in special listening techniques.

My final concern is the lack of a standard place for the patron to look for follow-up assistance. Depencling on the size of the area being circulated, locating the rover can add a complication to the inquiry process.

\section{Conclusion}

The reluctance of some patrons to approach a reference librarian when help is needed has long been acknowledged. I believe that inhouse outreach through roving can help librarians serve hesitant patrons. Because the rover is not involved in other duties, patrons have no reason to fear that the rover will be bothered if they ask for help. Those who suspect that their questions are too unimportant to take to a librarian may benefit, too. The rover's presence and offer of assistance signal interest in the question to those hesitant patronsthis may be all that is necessary to tip the balance toward asking the question. Even patrons who have been disappointed by past interaction with librarians may be less reluctant to "give them another chance" if assistance is directly offered.

Through friendly yet dogged reference roving at DVC's Library, I believe I have reached many otherwise underserved patrons with needed bibliographic instruction and reference assistance. At the same time, through this internship, I have become more skilled and confident at reference work. It is a win-win arrangement which I recommend to interns and their supervisors alike to advance the training of future librarians while serving the needs of patrons.

\section{(Internet cont. from page 353)}

Institute of Electrical and Electronics Engineers (IEEE): includes membership and chapter information (gopher.ieee.org, port 70 ).

IEEE Computer Society: includes calls for papers, membership information, and tables of contents for society publications (info. computer.org, port 70).

Society of Industrial and Applied Mathematics: includes advance conference programs and calls for papers, and book reviews (gopher.siam.org, port 70).

\section{Guides and updates}

A number of electronic sources are tracking engineering information on the networks. As the rate at which information sources become available online increases, the online sources for tracking them will be able to keep pace more reliably than print guides.

Engineering Virtual Library. This is a subject guide to WWW sources. The recent explosive growth in Mosaic applications makes this guide increasingly important; it is available at http://epims1.gsfc.nasa.gov/engineering/ engineering.html.

Library Without Walls. North Carolina State University's gopher server, the Library Without Walls includes subject guides to many disciplines including engineering. It is located at dewey.lib.ncsu.edu, port 70 , in the "Library Without Walls/Study Carrels" menu.

InfoSlug. The University of California-Santa Cruz maintains a gopher server named InfoSlug which includes a subject guide to research materials. It is at scilibx.ucsc.edu, port 70 , in the "The Researcher" menu.

University of Michigan SHS. The University of Michigan School of Information and Library Studies (SILS) has created several thorough subject guides to Internet resources, including aerospace engineering and environment issues. These are available at una.hh.lib. umich.edu, port 70, in the "inetdirs" directory

EINet Galaxy. EINet Galaxy provides a guide to many engineering sources via the WWW. The guide is available at http:// galaxy.einet.net/galaxy/Engineering-andTechnology.html. 